\title{
Estudo do uso de fontes de informação para inovação tecnológica na indústria brasileira
}

\author{
Cibele Roberta Sugahara \\ Professora da Faculdade de Administração da PUC-Campinas. \\ Bacharel em administração e mestre em biblioteconomia \\ e ciência da informação pela PUC-Campinas \\ E-mail: cibsrs@yahoo.com.br \\ Paulo de Martino Jannuzzi \\ Professor da Ence/IBGE e colaborador do Programa \\ de Pós-graduação em Ciência da Informação da PUC- \\ Campinas, doutor em demografia (Unicamp). \\ E-mail: pjannuzzi@mpc.com.br
}

\begin{abstract}
Resumo
O uso de fontes de informação internas e externas à empresa para a geração da inovação tecnológica é fator determinante para a competitividade de qualquer economia. O presente trabalho analisa a importância atribuída às fontes de informação internas e externas à empresa para a introdução de inovação tecnológica nas indústrias, a partir da Pesquisa Industrial de Inovação Tecnológica (Pintec - 2000) do IBGE, que investigou as atividades de inovação tecnológica em cerca de 70 mil indústrias brasileiras. As empresas foram instadas a avaliar o uso e importância de diferentes tipos de fontes de informação. Identificou-se na pesquisa o caráter secundário, em geral, das informações provenientes do departamento de pesquisa e desenvolvimento e das universidades e institutos de pesquisa e, em contrapartida, o papel fundamental das informações provenientes do mercado, concorrência e fornecedores. constatou-se também que a importância conferida e a diversidade de fontes consultadas (P\&D e universidades, inclusive) dependem do grau de competitividade do setor industrial, tendo desdobramentos importantes do ponto de vista do desempenho em inovação tecnológica.
\end{abstract}

\section{Palavras-chave}

Fontes de informação; Pesquisa industrial; Inovação tecnológica; Inovação tecnológica; pesquisa e desenvolvimento.

\section{Study on the use of information sources to technological innovation in brazilian manufactures}

\begin{abstract}
The use of internal and external sources of information to create technological innovation in companies is a crucial factor to the competitiveness of the any nation's economy. This paper analyses the importance of external and internal sources of information to innovation practices, by using Technological Industrial Innovation Research - Pintec 2000 from IBGE- that investigated the technological innovation activities in about seventy thousand brazilian manufactures. Companies were told to evaluate the use and importance of several types of sources of information. R\&D Departments and Universities are considered less important than information brought by Market agents. The data showed also that the importance and diversity of sources of information used including R\&D and Universities- depends on the industry competitiveness, yielding important impact on Technological Innovation rates.
\end{abstract}

\section{Keywords}

Information sources; Industrial research technological innovation: Technological innovation; Research and development.

\section{INTRODUÇÃO}

Em que pese o aumento significativo da produção científica de pesquisadores brasileiros, apontado por diferentes trabalhos (FAPESP, 2002; MUGNAINI et alii, 2004), o esforço nacional - público e privado - em ciência, tecnologia e informação (CT\&I) ainda não foi suficiente para a geração do conhecimento e da inovação tecnológica com potencial de desencadear impactos importantes para o desenvolvimento econômico do país. O número de patentes depositadas por brasileiros ou empresas aqui sediadas nos grandes mercados mundiais - indicador de dinamismo na pesquisa tecnológica e de inovação, - continua comparativamente baixo, assim como a parcela de gastos privados em Pesquisa de Desenvolvimento (P\&D).

A comparação de indicadores em CT\&I do Brasil com a Coréia é ilustrativa nesse sentido. No Brasil, em 2001, segundo dados da Organização Mundial de Propriedade Intelectual (Ompi) e do Instituto Nacional de Propriedade Intelectual (Inpi), o número de depósitos de patentes de invenção nos escritórios nacionais totalizava 13.653 na Ompi e 6.587 no Inpi. Já a Coréia em 2001 apresentou 104.612 depósitos de patentes de invenção nos escritórios nacionais*. Com relação aos investimentos em P\&D, enquanto na Coréia os gastos totalizavam, em meio à crise de 1999-2001, cerca de 2,7\% do seu produto interno bruto (DAHLMAN, 2002), no Brasil, a cifra equivalente no período não atingia o patamar de $1 \%$ (FAPESP, 2002). Parte desse diferencial deve-se à baixa participação do setor privado em investimentos em $P \& D$, já que, enquanto na Coréia os investimentos privados em $\mathrm{P} \& \mathrm{D}$ atingiam cerca de $80 \%$ do total nos anos 1990, no Brasil, a participação do setor privado em gastos nacionais em $P \& D$ representava $36 \%$ do montante total.

Esta baixa disposição para inovar e investir em $P \& D$ das empresas aqui sediadas tem sido explicada, em parte, pelas dificuldades de acesso às informações técnico-científicas e mercadológicas, entre a empresa privada, instituições de pesquisa, governo e universidades (MARCOVITCH, 1983). A troca de informações sobre os concorrentes, incentivos fiscais, políticas de subsídios à $P \& D$, licenças e patentes, por exemplo, podem estimular o desenvolvimento de tecnologias. Porém, para viabilizar esta troca, a empresa

\footnotetext{
* Disponível em: http://www.mct.gov.br/estat/ascavpp/portugues/9 Comparacoes/tabelas/tab9_4_1.htm, acesso em 27 de dezembro de 2004.
} 
privada precisa ter um certo vínculo com os demais atores do sistema e vice-versa. É a sinergia entre esses atores que cria condições para a troca de informações técnicocientíficas e mercadológicas.

É com o propósito de discutir o acesso e uso de informação provenientes de universidades, centros de pesquisa e outras fontes por parte das indústrias de transformação e extrativas brasileiras que se apresenta este trabalho. Mais especificamente, o presente estudo visa a analisar a intensidade e a diversidade no uso de fontes de informação internas e externas à empresa, com o objetivo de implementar inovação tecnológica em produtos e/ou processos, na forma possibilitada pela Pesquisa Industrial Inovação Tecnológica (Pintec, 2000) do IBGE. Iniciase o texto com uma apresentação da pesquisa, seus conceitos e características do levantamento amostral, passando-se, em seguida, para breve sistematização dos seus resultados quanto ao desempenho em inovação tecnológica das indústrias brasileiras. Nas duas seções seguintes, apresenta-se, então, a análise do uso das fontes de informação, abordando, primeiramente, uma perspectiva descritiva e, depois, uma perspectiva mais interpretativa, relacionando o uso das fontes e nível de competitividade empresarial.

\section{PINTEC: PRINCIPAIS DEFINIÇÕES}

A Pintec é a primeira pesquisa mais ampla no Brasil, referida ao contexto nacional, com conceitos internacionalmente comparáveis, que procurou retratar as atividades inovativas das indústrias brasileiras. Foi realizada pela Fundação Instituto Brasileiro de Geografia e Estatística (IBGE), em parceria com a Financiadora de Estudos e Projetos (Finep), referida ao período de 1998 a 2000*.

Como unidade de análise, a Pintec 2000 abrangeu todas as empresas que estavam registradas no Cadastro Nacional de Pessoa Jurídica do Ministério da Fazenda (CNPJ) e estão classificadas no Cadastro Central de Empresas (Cempre) do IBGE como industrial, que estão ativas e têm 10 ou mais pessoas ocupadas. Nesse contexto, conforme a Pintec 2000, a empresa é industrial quando a sua principal receita provém da atividade industrial.**

\footnotetext{
"Um dos estudos pioneiros sobre inovação tecnológica, realizado com base na metodologia da OCDE e com representatividade estatística, foi desenvolvido pelo Seade, encartado na Pesquisa de Atividade Econômica Paulista (Paep).

** O IBGE (2002) na classificação das atividades utilizou como referência a Classificação Nacional de Atividades Econômicas (Cnae). Na Pintec 2000 e para a análise das fontes de informação desta pesquisa, o âmbito populacional são as empresas que possuem principal receita derivada da atuação nas atividades das indústrias extrativas e indústrias de transformação (classificadas nas seções C e D do Cnae).
}

Como instrumento de coleta de informações, a pesquisa utilizou entrevistas assistidas presenciais e por telefone. Com a finalidade de garantir uniformidade no entendimento conceitual da inovação tecnológica, essas entrevistas foram realizadas com todas as empresas da amostra. Para obter uniformidade conceitual, o IBGE primeiramente identificou o informante, profissional da área de $P \& D$ ou produção industrial da empresa, com capacidade de assimilar os conceitos apreendidos na pesquisa e que possuísse as informações relevantes e requeridas no estudo ${ }^{* * *}$.

A Pintec define inovação tecnológica seguindo a recomendação internacional explicitada nos Manuais Frascatti. O Manual Frascati: Medição de Atividades Científicas e Tecnológicas (OCDE, 1976, p. 35) designa inovação tecnológica como sendo "[...] o êxito mercadológico de novos serviços ou produtos manufaturados, ou o uso comercial de novos processos técnicos."

Em edição posterior do referido manual, a inovação tecnológica

Inclui a implementação de novos produtos e processos e o aperfeiçoamento significativo em produtos e processos. Uma inovação tecnológica de produto e de processo é implementada quando for introduzida no mercado (inovação de produto) ou aplicada dentro de um processo produtivo (inovação de processo). As inovações de produto e de processo envolvem uma série de atividades científica, tecnológica, organizacional, financeira e comercial (OCDE, 1993, p. 5).

Na edição de 2002 do Manual Frascati, Proposed Standard Practice for Surveys on Research and Experimental Development, as atividades de inovação tecnológica envolvem

(...) todos os passos científico, tecnológico, organizacional, financeiro e comercial, incluindo investimentos em novo conhecimento, os quais, atualmente, são utilizados na implementação de produtos e processos tecnologicamente novos ou aperfeiçoados. P\&D é apenas uma dessas atividades e pode ser realizada em diferentes fases do processo de inovação (OCDE, 2002, p. 18).

\footnotetext{
*** É importante destacar que as entrevistas assistidas presenciais foram realizadas apenas nas empresas de grande porte (com 500 ou mais pessoas ocupadas) e localizadas nos estados do Amazonas, Alagoas, Bahia, Ceará, Pernambuco, Espírito Santo, Minas Gerais, Rio de Janeiro, São Paulo, Paraná, Rio Grande do Sul, Santa Catarina e Goiás, sendo adotadas, para as demais empresas, entrevistas por telefone.
} 
Seguindo tais definições, a Pintec reconhece uma inovação tecnológica como sendo a implementação de processos ou produtos (bens e serviços) tecnologicamente novos ou substancialmente aprimorados (IBGE, 2002). Essa implementação ocorre quando o produto é introduzido no mercado, ou o processo passa a ser operado pela empresa. Entende-se por produto tecnologicamente novo aquele cujas características fundamentais (especificações técnicas, usos pretendidos, software ou outro componente imaterial incorporado) diferem significativamente de todos os produtos previamente produzidos pela empresa.

A inovação de produto também pode ser progressiva, mediante significativo aperfeiçoamento tecnológico de produto previamente existente, cujo desempenho foi substancialmente aumentado ou aprimorado. Assim, por um lado, um produto simples pode ser aperfeiçoado (no sentido de obter melhor desempenho ou menor custo), com a utilização de matérias-primas ou componentes de maior rendimento. Por outro lado, um produto complexo, com vários componentes ou subsistemas integrados, pode ser aperfeiçoado via mudanças parciais em um dos seus componentes ou subsistemas. Essa definição não inclui as mudanças puramente estéticas ou de estilo, assim como a comercialização de produtos novos integralmente desenvolvidos e produzidos por outra empresa.

Na pesquisa, assume-se que a inovação tecnológica de processo está relacionada a um processo tecnologicamente novo ou substancialmente aprimorado, que envolve a introdução de tecnologia de produção nova ou significativamente aperfeiçoada, assim como métodos novos ou substancialmente aprimorados de manuseio, e entrega de produtos (acondicionamento e preservação). A adoção desses métodos pode acarretar mudanças nas máquinas e equipamentos e/ou na organização produtiva (desde que acompanhada de mudanças no processo técnico de transformação do produto) e trazer resultados relevantes em relação ao nível e à qualidade do produto, ou custos de produção e entrega. Porém, a decisão em adotar esses métodos pode ter por finalidade produzir ou entregar produtos tecnologicamente novos ou substancialmente aprimorados que não podem utilizar os processos previamente existentes ou aumentar a eficiência da produção e da entrega de produtos já existentes. Não fazem parte desse conceito as mudanças pequenas ou rotineiras nos processos produtivos existentes, e aquelas puramente administrativas ou organizacionais, a criação de redes de distribuição e os desenvolvimentos necessários para comércio eletrônico de produtos.

Na pesquisa, as fontes de informação levantadas como subsídio ao processo de inovação pelas empresas foram classificadas em fontes de informação internas e fontes de informação externas. Em relação às fontes internas, a Pintec 2000 dividiu em informações oriundas dos departamentos de pesquisa e desenvolvimento e informações de outras áreas internas à empresa. Já as fontes externas incluem outra empresa do grupo, fornecedores, clientes ou consumidores, concorrentes, empresas de consultoria e consultores independentes, universidades e institutos de pesquisa, centros de capacitação profissional e assistência técnica, instituições de testes, ensaios e certificações, licenças, patentes e know-how, conferências, encontros e publicações especializadas, feiras e exposições e redes de informações informatizadas.

Os fornecedores, clientes ou consumidores, concorrentes e outras empresas do grupo fazem parte das fontes ligadas às atividades de mercado. As feiras e exposições, conferências, encontros e publicações especializadas, assim como as redes de informações informatizadas, são fontes de caráter profissional. As atividades realizadas para a aquisição de licenças, patentes e know-how realizadas por universidades e institutos de pesquisa e empresas de consultoria são denominadas fontes especializadas e institucionais.

No levantamento, solicitou-se às empresas que implementaram inovação a atribuição do grau de importância para essas fontes anteriormente relacionadas. Vale observar que na pesquisa investigou-se o grau de importância atribuído às diversas fontes, e não o uso efetivo como foi investigado, por exemplo, na pesquisa "Demanda por informação tecnológica pelo setor produtivo", realizada pela Confederação Nacional da Indústria (1996). Para finalidade analítica deste trabalho, o grau de importância foi categorizado da seguinte forma: alta / média e baixa / não relevante.

\section{INOVAÇÃO TECNOLÓGICA DAS EMPRESAS INDUSTRIAIS BRASILEIRAS: PRINCIPAIS RESULTADOS}

Os dados da Pintec mostram que, do universo de 72.005 empresas industriais pertencentes aos setores de transformação e extrativa, somente 22.698 (31,5\% do total) registraram inovações no período entre 1998 e 2000. Tal resultado explica-se pela taxa média de inovação nas empresas industriais de transformação (31,9\%), já que nas indústrias extrativas a cifra correspondente é substancialmente menor (17,2\%).

As diferenças da dinâmica inovadora nas empresas analisadas podem ser entendidas pela natureza da atividade industrial praticada pelo setor. Como era de se esperar, os setores da indústria que utilizam mais intensamente 
conhecimentos técnico-científicos no desempenho de suas atividades são os que em geral apresentam taxas de inovação acima de 50\%, destacando as indústrias fabricantes de máquinas para escritório e equipamentos de informática $(68,5 \%)$, as fabricantes de material eletrônico e de aparelhos e equipamentos de comunicações $(62,5 \%)$, assim como o fabricante de equipamentos de instrumentação médico-hospitalares, instrumentos de precisão e ópticos, equipamentos para automação industrial, cronômetros e relógios $(59,1 \%)$, conforme tabela 1 , a seguir.

Segundo Coutinho e Ferraz (1995), o complexo eletrônico, composto por informática, telecomunicações, automação industrial e software, e o complexo químico, composto por fármacos e defensivos agrícolas, são classificados difusores de progresso técnico, por serem a base do novo modelo técnicoindustrial. Em outras palavras, são fontes de inovações e progresso técnico para outras indústrias. Entretanto, para viabilizar a difusão do progresso técnico, é necessário realizar investimentos que decorrem do dinamismo da economia, dos programas de financiamento a longo prazo e da coordenação de políticas industrial e tecnológica.

Nos setores das indústrias intensivas em escala e/ ou caracterizadas por processos contínuos, a taxa de inovação varia entre $30 \%$ a $50 \%$, como se pode observar nos segmentos da metalúrgica básica, cadeia química, fabricação de coque, refino de petróleo e fabricação de artigos de borracha e plástico. O sistema produtivo destes setores é caracterizado pela exploração de recursos minerais, agrícolas, florestais e energéticos e também pelo uso de mãode-obra. Apesar da capacidade competitiva desses setores em termos de produção em escala, existem desigualdades, principalmente em relação à capacitação tecnológica, financeira e comercial, evidenciando o despreparo para atuarem com o mesmo grau de sucesso nos mercados de maior valor agregado* (COUTINHO; FERRAZ, 1995).

O grupo de indústrias que apresenta taxa de inovação inferior a $30 \%$, como, por exemplo, as fabricantes de produtos de madeira e confecções de artigos do vestuário e acessórios, é em boa medida, o que Coutinho e Ferraz (1995) consideram como setores com deficiências competitivas. E são assim classificados por terem grande parte da produção originada de empresas pouco competitivas. Isso decorre de as empresas operarem com equipamentos obsoletos, não praticarem conceitos de qualidade e possuírem elevados níveis de capacidade ociosa, restringindo, assim, a introdução de inovação de produtos e processos. Essas deficiências competitivas são caracterizadas

\footnotetext{
*Vale observar que a avaliação do panorama da indústria nacional, de Coutinho e Ferraz (1995), intitulada Estudo da Competitividade da Indústria Brasileira, retrata o cenário das indústrias no final da década de 1980. No entanto, é importante observar que algumas indústrias a partir da década de 1990 podem ter apresentado melhor desempenho inovador.
}

pela heterogeneidade da estrutura produtiva dentro de uma mesma indústria. É o caso, por exemplo, do segmento de confecção de artigos do vestuário e acessórios, no qual apenas $26,2 \%$ do total das empresas apresentaram inovações. As limitações da indústria têxtil quanto à ampliação da sua competitividade justifica-se tanto pela carência de métodos gerenciais modernos, que possibilitem maior flexibilidade produtiva e atualização dos produtos, quanto pela ausência de instrumentos que viabilizem o acesso cooperativo às informações de mercado. Estes instrumentos contribuem para a promoção de maior capacitação tecnológica e gerencial, minimizando as desvantagens de escala entre as pequenas e médias empresas (COUTINHO; FERRAZ, 1995).

Outra dimensão que permite compreender a propensão a inovar das indústrias brasileiras é a relação existente entre o desempenho inovador e o porte da empresa. Constata-se, nos dados da tabela 2, a seguir, que o desempenho varia substancialmente conforme o porte, sendo a proporção da taxa de inovação crescente com o tamanho da empresa. Assim, nas empresas que ocupam de 10 a 99 pessoas" (aqui consideradas pequenas empresas), a taxa de inovação é $28,6 \%$, enquanto as empresas com 500 pessoas ou mais (grandes empresas) apresentam taxa média de inovação de 75,6\%. A concentração de empresas de pequeno porte, correspondente a $80,8 \%$ do universo de 72.005 empresas, contribui para abaixar a taxa média de inovação no país.

As evidências empíricas tratadas nesse tópico sugerem que o desempenho inovador é influenciado principalmente por fatores relacionados ao tipo de atividade desenvolvida pela empresa e ao porte. Uma das hipóteses desse trabalho é que a inovação nas indústrias brasileiras é determinado pela forma de uso dos diferentes tipos de fontes de informação, classificadas na Pintec 2000 como fontes de informação interna e fontes de informação externas. A relação entre a importância no uso destas fontes e o desempenho inovador é discutida nos próximos tópicos.

\section{ANÁLISE DO USO DE FONTES INTERNAS E EXTERNAS DE INFORMAÇÃO}

Um resultado um tanto surpreendente da Pintec 2000 é que apenas $13,0 \%$ do total de empresas inovadoras atribuem alta/média importância ao departamento de $P \& D$ como fonte de informação para inovação. Nas indústrias extrativas, a cifra equivalente é ainda menor: $10,4 \%$ apenas das empresas consideram esta

\footnotetext{
"Na classificação do porte foi utilizada a pesquisa da Confederação Nacional das Indústrias (CNI, 1996) "Demanda por informação tecnológica pelo setor produtivo". Nessa pesquisa, as empresas que ocupam de 10 a 99 empregados são consideradas empresas de pequeno porte, as que ocupam de 100 a 499 empregados são classificadas de médio porte, e as que ocupam acima de 500 pessoas são consideradas de grande porte.
} 
Estudo do uso de fontes de informação para inovação tecnológica na indústria brasileira

\section{TABELA 1}

Empresas industriais do setor de transformação, segundo classe da taxa de inovação - Brasil, 1998-2000

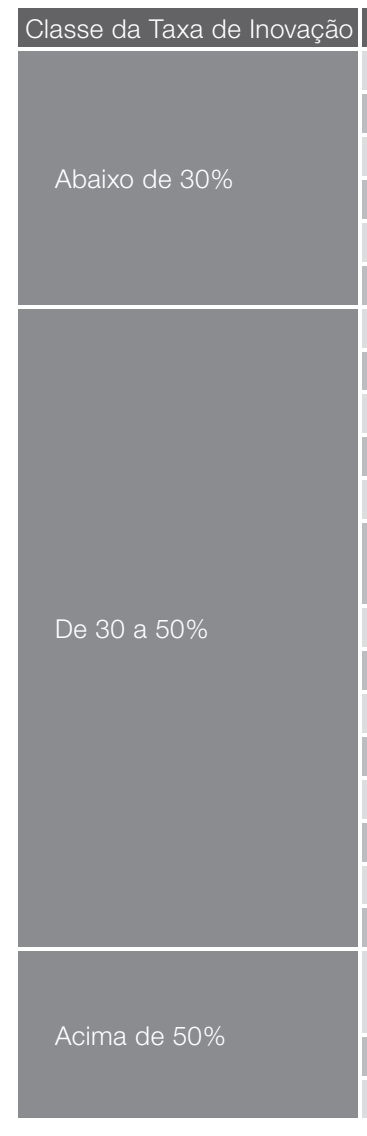

\begin{tabular}{|l}
\hline Atividades das indústrias de transformação \\
\hline Reciclagem \\
\hline Fabricação de produtos de madeira \\
\hline Fabricação de produtos de minerais não-metálicos \\
\hline Fabricação de celulose, papel e produtos de papel \\
\hline Confecção de artigos do vestuário e acessórios \\
\hline Fabricação de produtos alimentícios e bebidas \\
\hline Metalurgia básica \\
\hline Fabricação de produtos têxteis \\
\hline Fabricação de produtos de metal \\
\hline Edição, impressão e reprodução de gravações \\
\hline Preparação de couros e fabricação de artefatos de couro, artigos de viagem e calçados \\
\hline Fabricação de coque, refino de petróleo, elaboração de \\
\hline combustíveis nucleares e produção de álcool \\
\hline Fabricação de móveis e indústrias diversas \\
\hline Fabricação de produtos do fumo \\
\hline Fabricação e montagem de veículos automotores, reboques e carrocerias \\
\hline Fabricação de artigos de borracha e plástico \\
\hline Fabricação de outros equipamentos de transporte \\
\hline Fabricação de máquinas e equipamentos \\
\hline Fabricação de produtos químicos \\
\hline Fabricação de máquinas, aparelhos e materiais elétricos \\
\hline Fabricação de equipamentos de instrumentação médico-hospitalares, instrumentos de \\
precisão e ópticos, equipamentos para automação industrial, cronômetros e relógios \\
\hline Fabricação de material eletrônico e de aparelhos e equipamentos de comunicações \\
\hline Fabricação de máquinas para escritório e equipamentos de informática \\
\hline
\end{tabular}

\begin{tabular}{|l|}
\hline 13,1 \\
\hline 14,3 \\
\hline 24,0 \\
\hline 26,2 \\
\hline 29,5 \\
\hline 31,4 \\
\hline 31,9 \\
\hline 32,8 \\
\hline 33,1 \\
\hline 33,6 \\
\hline 33,6 \\
\hline 34,4 \\
\hline 34,8 \\
\hline 36,4 \\
\hline 39,7 \\
\hline 43,7 \\
\hline 44,4 \\
\hline 46,1 \\
\hline 48,2 \\
\hline 59,1 \\
\hline 62,5 \\
\hline 68,5 \\
\hline
\end{tabular}

Fonte: Pintec, 2000

\section{TABELA 2}

Empresas que implementaram inovação e taxa de inovação das indústrias de transformação e extrativas, segundo porte - Brasil, 1998-2000

\begin{tabular}{lccc} 
Porte & Empresas Industriais & Empresas que implementaram inovações & Taxa de Inovação (\%) \\
\hline Total & 72.005 & 22.698 & 31,5 \\
Pequena & 64.168 & 18.339 & 28,6 \\
Média & 6.475 & 3.329 & 51,4 \\
Grande & 1.360 & 1.029 & 75,6
\end{tabular}

Fonte: Pintec 2000

fonte relevante. Pelo que mostra a pesquisa, as empresas conferem maior destaque às outras áreas internas à empresa na busca de informação para inovação. De fato, essa fonte é referenciada por $68,7 \%$ do total das empresas inovadoras como de alta/média importância.

Na realidade, este resultado não deveria surpreender, já que, como mostram Tidd et alii (2001), são as empresas pertencentes aos setores intensivos em conhecimento que geralmente realizam mais atividades formais de $P \& D$, disponibilizando parcela considerável de seus rendimentos a tais atividades, como ocorre, por exemplo, com o setor farmacêutico. Já as empresas pertencentes ao setor do vestuário estão mais orientadas para o mercado, priorizando os clientes como fontes de informação. Pelo fato de nem todas as empresas investirem em P\&D, surge o desafio de encontrarem um caminho para usar a tecnologia gerada pelos outros ou complementarem internamente seu núcleo de tecnologia. As empresas podem até sobreviver sem 
capacitação interna para gerar tecnologia, no entanto, para suprir tal deficiência, necessitam desenvolver boa rede de fontes externas e habilidades para utilizar efetivamente a tecnologia externa adquirida.

As informações provenientes de fontes externas são, de modo geral, consideradas mais relevantes quando comparadas às informações provenientes do departamento de P\&D. Como se pode observar nos dados da tabela 3 , as fontes relacionadas às atividades de mercado são citadas por $45 \%$ do total de empresas inovadoras como de maior relevância para inovação. Em seguida, surgem em ordem de importância as fontes de caráter profissional com $44 \%$, e as fontes especializadas e institucionais $(12,1 \%)$. Como observa Araújo (1979, p.84), grande parte das idéias bem-sucedidas e implementadas pelas empresas são provenientes de fontes externas. A autora, com base em outra pesquisa, enfatiza que,

enquanto canais de comunicação e recursos técnicos internos altamente desenvolvidos são vitais para o sucesso na resolução de problemas, o fluxo de informação do meio ambiente externo é também crítico para soluções técnicas eficazes.

Ao compararmos o grau de importância das fontes ligadas às atividades de mercado e de caráter profissional em relação às fontes especializadas e institucionais, observase que a estratégia das empresas para o desenvolvimento da inovação é baseada principalmente nas relações comerciais. As fontes relacionadas com as atividades de mercado identificadas de maior relevância para inovação na Pintec 2000 foram, em ordem crescente, os fornecedores (citadas por $66,1 \%$ das indústrias), clientes ou consumidores (59,5\%) e concorrentes $(47,8 \%)$. Quanto aos fornecedores, observa-se que, de modo geral, o grau de importância alta/média deste quesito entre as indústrias de transformação e extrativa quase não se altera (representando 66\% e 69,6\% das indústrias, respectivamente).

Esse comportamento também pode ser observado quanto à importância conferida aos concorrentes em ambos os setores. Já em relação aos clientes ou consumidores, as informações procedentes destas fontes são citadas como relevantes por $59,7 \%$ das indústrias de transformação e $39,2 \%$ das indústrias extrativas. Tal quadro se justifica, como era de se esperar, pelo fato de os produtos desenvolvidos nas indústrias de transformação serem direcionados ao consumidor final.

Tais cifras revelam que, ao oferecerem atenção especial aos fornecedores e clientes ou consumidores como principais fontes externas para inovação, as empresas priorizam o aperfeiçoamento de produtos/serviços pela incorporação de atributos considerados relevantes pelo mercado. É a troca de informações entre estes atores quanto à qualidade e desempenho dos produtos e processos e o estabelecimento de cooperação entre fornecedores e empresas, por exemplo, que possibilita o desenvolvimento da inovação (COUTINHO; FERRAZ, 1995).

Quanto às fontes que compõem as atividades de caráter profissional, é interessante destacar que nesta categoria as feiras e exposições são citadas como as mais relevantes. A percepção da importância desta fonte para inovação corresponde a $61,8 \%$ das indústrias de transformação e $55,8 \%$ das extrativas. Tal fato justifica-se, como observa Araújo (1983), em função da importância da comunicação interpessoal que esses tipos de eventos proporcionam.

Já em relação às conferências e publicações especializadas, a importância do uso das informações destas fontes é mais expressiva nas indústrias extrativas, se comparada à conferida pelas indústrias de transformação (citadas por $41 \%$ e $37,4 \%$ das indústrias respectivamente). Em seguida, os dados da tabela 3, a seguir, evidenciam que, dentre as informações provindas de fontes de caráter profissional, as redes de informações informatizadas são as de menor importância para inovação, sendo consideradas relevantes por apenas $33,1 \%$ do total das indústrias.

No que diz respeito às fontes que compõem as atividades especializadas e institucionais, convém destacar que, dentre as fontes desta categoria, surpreendentemente as licenças e patentes são referidas como as de menor importância para inovação (apenas 6,5\% das indústrias consideram esta fonte importante). Quanto à percepção das empresas em relação à relevância das informações provenientes das universidades, apenas $11,4 \%$ do total das inovadoras conferem maior importância a esta fonte. No entanto, é interessante ressaltar que esta importância é mais acentuada nas indústrias extrativas (citadas por 19,5\% das indústrias). Em relação aos centros de capacitação e instituições de testes, o enfoque da importância sobre as informações destas fontes é mais expressivo, sendo caraterizadas como de importância alta/média por respectivamente 16,6\% e $15 \%$ do total das indústrias.

A inexpressiva importância conferida às licenças e patentes e universidades como fontes de informação mostra a fraca interação existente entre empresas e instituições públicas de pesquisa, além de evidenciar os obstáculos para aprofundar os esforços de inovação e explorar novas oportunidades tecnológicas, como observou Quadros (1999), com base em outra pesquisa. 
Estudo do uso de fontes de informação para inovação tecnológica na indústria brasileira

\section{TABELA 3:}

Grau de importância alta/média das fontes de informação internas e externas empregada pelas indústrias extrativas e de transformação - Brasil, 1998-2000

\begin{tabular}{|c|c|c|c|}
\hline FONTES INTERNAS E EXTERNAS & INDÚSTRIA EXTRATIVA & INDÚSTRIA DE TRANSFORMAÇÃO & TOTAL \\
\hline Total de Empresas : & 297 & 22.401 & 22.698 \\
\hline \multicolumn{4}{|l|}{ FONTES INTERNAS } \\
\hline Departamento de P\&D & $10,4 \%$ & $13,1 \%$ & $13,0 \%$ \\
\hline Outras Áreas & $70,3 \%$ & $67,8 \%$ & $68,7 \%$ \\
\hline \multicolumn{4}{|l|}{ FONTES EXTERNAS } \\
\hline Atividades de Mercado & $40,8 \%$ & $45,0 \%$ & $45,0 \%$ \\
\hline Outras Empresas do Grupo & $9,0 \%$ & $6,5 \%$ & $6,6 \%$ \\
\hline Fornecedores & $69,6 \%$ & $66,0 \%$ & $66,1 \%$ \\
\hline Clientes ou Consumidores & $39,2 \%$ & $59,7 \%$ & $59,5 \%$ \\
\hline Concorrentes & $45,3 \%$ & $47,8 \%$ & $47,8 \%$ \\
\hline Especializadas e Institucionais & $17,9 \%$ & $12,0 \%$ & $12,1 \%$ \\
\hline Empresas de Consultoria & $32,6 \%$ & $10,5 \%$ & $10,8 \%$ \\
\hline Universidades & $19,5 \%$ & $11,3 \%$ & $11,4 \%$ \\
\hline Centros de Capacitação & $10,1 \%$ & $16,7 \%$ & $16,6 \%$ \\
\hline Instituições de Testes & $24,9 \%$ & $14,9 \%$ & $15,0 \%$ \\
\hline Licenças e Patentes & $2,1 \%$ & $6,5 \%$ & $6,5 \%$ \\
\hline Caráter Profissional & $41,9 \%$ & $44,1 \%$ & $44,1 \%$ \\
\hline Conferências e Publicações Especializadas & $41,0 \%$ & $37,4 \%$ & $37,4 \%$ \\
\hline Feiras e Exposições & $55,8 \%$ & $61,8 \%$ & $61,7 \%$ \\
\hline Redes de Informações Informatizadas & $29,0 \%$ & $33,1 \%$ & $33,1 \%$ \\
\hline
\end{tabular}

Fonte: Pintec, 2000

Uma análise mais detalhada dos resultados da pesquisa, como apresentada na tabela 4 , a seguir, revela que, na maioria dos setores com desempenho inovador inferior à média industrial, as informações provindas do departamento de $\mathrm{P} \& \mathrm{D}$ assumem caráter de menor importância para inovação. Em termos percentuais, podese observar a pouca importância atribuída a esta fonte, principalmente nos segmentos das atividades de reciclagem (100\% das indústrias atribuíram grau baixo e não relevante à $P \& D)$, fabricação de produtos de madeira $(97,1 \%)$, confecção de artigos do vestuário e acessórios (95,5\%). Talvez isso se explique pela natureza menos complexa das atividades desenvolvidas por estas indústrias.

Tal tendência contrasta com as fabricantes de celulose, papel e produtos de papel, que, apesar de apresentarem desempenho inovador abaixo da média, apontam no sentido de maior utilização de informações produzidas pelo departamento de $\mathrm{P} \& \mathrm{D}(16,5 \%$ das indústrias deste segmento consideram esta fonte de alta / média importância).

Em contrapartida, na maioria dos setores com taxa de inovação entre $30 \%$ a $50 \%$, os dados da pesquisa indicam que as empresas industriais conferem maior relevância ao departamento de $\mathrm{P} \& \mathrm{D}$ na busca por informação. Dentre aquelas que atribuíram alta/média importância a esta fonte, destacam-se as fabricantes de produtos químicos (para 33,2\% das indústrias esta fonte é importante), montagem de outros equipamentos de transporte $(28,1 \%)$, produtos do fumo $(25,1 \%)$, máquinas, aparelhos e materiais elétricos (24,3\%), e máquinas e equipamentos $(20,1 \%)$. A percepção da importância dessa fonte de informação interna é mais expressiva nas indústrias que apresentam taxa de inovação acima de 50\%, como as fabricantes de máquinas para escritório e equipamentos de informática ( em 49,3\% das indústrias a P\&D é importante), material eletrônico e aparelhos e equipamentos de comunicações $(32,6 \%)$, e equipamentos e instrumentação médico-hospitalares, instrumentos de precisão e ópticos, equipamentos para automação industrial, cronômetros e relógios (31,4\%).

Diante dessa realidade, embora as empresas com taxa de inovação acima de 30\% tenham explicitado maior importância à $\mathrm{P \& D}$, o direcionamento de esforços para potencializar o uso das informações desta fonte parece assumir caráter secundário nas estratégias das indústrias brasileiras. Contudo, os dados acima evidenciam que o esforço inovador endógeno - associado à importância do uso de informações produzidas pelo Departamento de P\&D - implica melhor desempenho inovador. 
Com relação ao uso das fontes de informação externas, observa-se que, de modo geral, nas fabricantes de coque e refino de petróleo, máquinas para escritório e equipamentos de informática, máquinas, aparelhos e materiais elétricos, montagem de veículos automotores, reboques e carrocerias e de equipamentos de instrumentação médico hospitalares, as fontes relacionadas com as atividades de mercado apresentam importância de uso mais expressiva em comparação ao atribuído pelos demais setores. É oportuno mencionar que as fontes especializadas e institucionais são referidas com maior grau de importância especificamente nas fabricantes de coque, refino de petróleo, elaboração de combustíveis nucleares e produção de álcool e nas fabricantes de máquina para escritório e equipamentos de informática (citadas por $27,4 \%$ e $27,7 \%$ das indústrias, respectivamente).

Pode-se supor que o maior grau de importância dado às fontes especializadas e institucionais pelo setor de coque e refino de petróleo está relacionado às iniciativas da Petrobras*. Na década de 1950, a Petrobras implementou Centros de Pesquisas e Desenvolvimento (Cenpes), objetivando a formação e o desenvolvimento de recursos humanos. Outra iniciativa foi a criação de centros de excelência* ${ }^{* *}$ que contempla a participação de uma ou várias universidadesâncora, tendo por finalidade completar ou suprir as pesquisas necessárias, o estabelecimento de cursos de graduação e pós-graduação, assim como de sub-redes de pesquisa.

\footnotetext{
" Petrobras. Disponível em: http://www2.petrobras.com.br/portal/tecnologia. htm. Acesso em: 9 out. 2003.

** Um centro de excelência funciona como uma rede de instituições atuando em conjunto, em busca de excelência em uma determinada área do conhecimento. Cada centro de excelência une a empresa-líder, uma universidade, empresas nacionais e o governo, que participa com seus projetos. A empresa líder passa a ser uma espécie de laboratório ativo e cabe à universidade criar uma rede sobre o tema. Disponível em: http:// www2.petrobras.com.br/portal/tecnologia.htm . Acesso em: 9 out. 2003.
}

\section{TABELA 4}

Grau de importância alta/média das fontes internas e externas de informação atribuída pelas empresas que implementaram inovação, segundo as atividades da indústria de transformação - Brasil, 1998-2000

\begin{tabular}{|c|c|c|c|c|}
\hline Setor da Indústria & Depto P\&D & $\begin{array}{l}\text { Outras Áreas } \\
\text { da Empresa }\end{array}$ & $\begin{array}{l}\text { Atividades de } \\
\text { Mercado }\end{array}$ & $\begin{array}{l}\text { Especializadas } \\
\text { e Institucionais }\end{array}$ \\
\hline Total & $13,0 \%$ & $68,7 \%$ & $45,0 \%$ & $12,1 \%$ \\
\hline Indústrias de transformação & $13,0 \%$ & $67,8 \%$ & $45,0 \%$ & $12,0 \%$ \\
\hline Reciclagem & $0,0 \%$ & $85,9 \%$ & $31,0 \%$ & $0,0 \%$ \\
\hline Fab. de produtos de madeira & $2,9 \%$ & $72,8 \%$ & $46,1 \%$ & $10,0 \%$ \\
\hline Fab. de produtos de minerais não-metálicos & $12,5 \%$ & $59,5 \%$ & $43,3 \%$ & $11,3 \%$ \\
\hline Fab. de celulose, papel e produtos de papel & $16,5 \%$ & $61,5 \%$ & $47,8 \%$ & $9,8 \%$ \\
\hline Confecção de artigos do vestuário e acessórios & $4,5 \%$ & $56,1 \%$ & $44,0 \%$ & $10,0 \%$ \\
\hline Fab. de produtos alimentícios e bebidas & $10,3 \%$ & $61,7 \%$ & $43,1 \%$ & $13,9 \%$ \\
\hline Metalurgia básica & $10,6 \%$ & $88,2 \%$ & $44,1 \%$ & $14,8 \%$ \\
\hline Fab. de produtos têxteis & $15,1 \%$ & $65,2 \%$ & $45,7 \%$ & $10,2 \%$ \\
\hline Fab. de produtos de metal & $9,6 \%$ & $64,2 \%$ & $42,8 \%$ & $8,3 \%$ \\
\hline Edição, impressão e reprodução de gravações & $1,6 \%$ & $72,4 \%$ & $44,0 \%$ & $4,9 \%$ \\
\hline $\begin{array}{l}\text { Preparação de couros e fabricação de artefatos } \\
\text { de couro, artigos de viagem e calçados }\end{array}$ & $10,8 \%$ & $81,0 \%$ & $46,9 \%$ & $14,2 \%$ \\
\hline $\begin{array}{l}\text { Fab. de coque, refino de petróleo, elaboração de } \\
\text { combustíveis nucleares e produção de álcool }\end{array}$ & $5,7 \%$ & $85,6 \%$ & $52,0 \%$ & $27,4 \%$ \\
\hline Fab. de móveis e indústrias diversas & $6,7 \%$ & $66,0 \%$ & $46,2 \%$ & $11,1 \%$ \\
\hline Fab. de produtos do fumo & $25,1 \%$ & $51,2 \%$ & $47,3 \%$ & $5,4 \%$ \\
\hline Fab. e montagem de veículos automotores, reboques e carrocerias & $17,8 \%$ & $68,3 \%$ & $51,2 \%$ & $15,7 \%$ \\
\hline Fab. de artigos de borracha e plástico & $11,6 \%$ & $65,5 \%$ & $42,4 \%$ & $8,9 \%$ \\
\hline Fab. de outros equipamentos de transporte & $28,1 \%$ & $88,3 \%$ & $42,8 \%$ & $6,6 \%$ \\
\hline Fab. de máquinas e equipamentos & $20,1 \%$ & $80,2 \%$ & $45,6 \%$ & $14,3 \%$ \\
\hline Fab. de produtos químicos & $33,2 \%$ & $81,2 \%$ & $46,4 \%$ & $18,4 \%$ \\
\hline Fab. de máquinas, aparelhos e materiais elétricos & $24,3 \%$ & $65,1 \%$ & $51,5 \%$ & $14,1 \%$ \\
\hline $\begin{array}{l}\text { Fab. de eqtos. de instrumentação médico-hospitalares, } \\
\text { instrumentos de precisão e ópticos, ind. cronôm/relógios }\end{array}$ & $31,4 \%$ & $66,0 \%$ & $50,4 \%$ & $19,5 \%$ \\
\hline $\begin{array}{l}\text { Fab. de material eletrônico e de aparelhos e } \\
\text { equipamentos de comunicações }\end{array}$ & $32,6 \%$ & $74,7 \%$ & $43,2 \%$ & $12,6 \%$ \\
\hline Fab. de máquinas para escritório e equipamentos de informática & $49,3 \%$ & $53,3 \%$ & $51,9 \%$ & $27,7 \%$ \\
\hline
\end{tabular}

Fonte: Pintec, 2000 
O estudo sugere, portanto, que ao realizarem maior uso de informações provenientes das empresas com as quais se relacionam comercialmente, as indústrias estão propensas a maior participação em processos de incorporação e de adaptação de tecnologias. Ou seja, a baixa importância do uso de informações geradas pelas instituições de produção de conhecimento tecnológico como as universidades e institutos de pesquisa deve estar associada a menor participação das indústrias no desenvolvimento de inovações de produtos e/ou processos originais.

\section{ANÁLISE DA RELAÇÃO ENTRE INOVAÇÃO, COMPETITIVIDADE E USO DE FONTES DE INFORMAÇÃO}

A análise da intensidade de uso das fontes de informação, segundo grau de importância conferido pelas empresas inovadoras brasileiras, reforça a hipótese de que a habilidade para inovar é influenciada pela capacidade de as empresas absorverem e combinarem informações variadas de fontes internas e externas. No caso brasileiro, como visto no tópico anterior, a intensidade do uso de fontes relacionadas às atividades de mercado e de caráter profissional é mais expressiva, se comparada ao uso do departamento de P\&D e de fontes especializadas e institucionais.

Observa-se na tabela 5, a seguir, que, no grupo de indústrias identificadas com desempenho inovador acima de 50\% categorizado como de alta inovação -, 34,1\% do total das empresas referenciam o departamento de P\&D como fonte de informação significativa para inovação. Nos grupos de indústrias classificados com média (taxa de inovação entre $30 \%$ a $50 \%$ ) e baixa inovação (abaixo de 30\%), a importância do departamento de P\&D é substancialmente menor, citada por respectivamente $14,3 \%$ e $8,5 \%$ das indústrias. Quanto às outras áreas internas à empresa, os dados indicam que é consensual entre as três classes de indústrias a relevância das informações produzidas por estas fontes. Convém destacar a pouca variação do grau de importância atribuída a estas informações entre as três classes de indústrias.

Pode-se observar que, de modo geral, na classe de indústrias com inovação acima de 50\%, atribui-se maior importância às fontes de informação externas. No que se refere às informações provenientes dos fornecedores, estas são identificadas como de menor relevância na classe de alta inovação, se comparadas às classes de média e baixa inovação. Quanto à relevância das informações provindas de empresas de consultoria, é importante referir que esta é maior na classe de indústrias com alta inovação (citadas como relevantes por $14,3 \%$ das indústrias).
Em relação à universidade e institutos de pesquisa, observa-se que o reconhecimento da importância destas fontes de informação aumenta significativamente no grupo de indústrias com alta inovação (citadas como relevantes por $24 \%$ das empresas). Já nas indústrias de média e baixa inovação, a importância do uso destas fontes é substancialmente menor: apenas 10,4\% e $11,6 \%$, respectivamente das indústrias, consideram-nas relevante. No caso dos centros de capacitação profissional, é interessante destacar que a importância do uso de informações desta fonte é mais intensa nas indústrias com baixa inovação (considerada relevante por $20,2 \%$ das indústrias). Outra fonte de inovação considerada importante, especificamente pela classe de indústrias com alta inovação, refere-se às instituições de testes, ensaios e certificações (citadas como relevante por 23,1\% das indústrias).

Quanto às informações sobre licenças e patentes, observase que a relevância do uso desta fonte é predominante nas classes de indústrias mais inovadoras, como era de se esperar. É importante mencionar que as informações técnicas dos inventos patenteados podem estar disponíveis antes da inserção do produto no mercado. Além disso, como observou França (1997, p. 252), o conjunto de documentos sobre patentes de determinado setor permite evidenciar a evolução do estado-da-arte dos inventos neste setor direcionando novos caminhos de P\&D. Além das feiras e exposições, as conferências e publicações especializadas e redes de informações informatizadas são fontes de informação expressivas para as indústrias com alta inovação. É interessante observar que o grau de importância destas fontes decresce à medida que diminui a classe da taxa de inovação.

A análise do uso de fontes internas, segundo a tipologia de setores industriais proposta por Coutinho e Ferraz (1995), é adequada para verificar a relação entre competitividade e uso do P\&D. No estudo sobre a competitividade da indústria brasileira já citado, os autores categorizaram os setores industriais da seguinte forma: setores com deficiências competitivas - fabricantes de produtos têxteis, produtos de madeira, produtos minerais não-metálicos, outros equipamentos de transporte, móveis e indústrias diversas, confecção de artigos do vestuário e acessórios, fabricação de couro, edição, impressão e reprodução de gravações e montagem de veículos automotores; setores com capacidades competitivas - fabricação de celulose e papel, coque e refino de petróleo, produtos químicos, produtos de metal e metalurgia básica; setores difusores do progresso técnico como as fabricantes de máquinas e equipamentos, máquinas para escritório e equipamentos de informática, máquinas, aparelhos e materiais elétricos e material eletrônico e de aparelhos e equipamentos de comunicações. 


\section{TABELA 5}

Percentual de empresas inovadoras da indústria de transformação que atribuíram importância alta/média às fontes internas e externas de informação, segundo classe da taxa de inovação - Brasil, 1998-2000

\begin{tabular}{|c|c|c|c|c|}
\hline \multirow{2}{*}{ FONTES INTERNAS E EXTERNAS } & \multicolumn{4}{|c|}{ Classe da taxa de inovação } \\
\hline & Abaixo de $30 \%$ & Entre $30 \%$ a $50 \%$ & Acima de $50 \%$ & Total \\
\hline Total & 100,0 & 100,0 & 100,0 & \\
\hline Outras Áreas Internas à Empresa & 67,8 & 71,7 & 60,7 & 67,8 \\
\hline Outras Empresas do Grupo & 3,8 & 7,2 & 18,9 & 6,5 \\
\hline Fornecedores & 66,2 & 66,6 & 56,1 & 66,0 \\
\hline Concorrentes & 53,3 & 45,2 & 40,6 & 47,8 \\
\hline Empresas de Consultoria & 10,2 & 10,4 & 14,3 & 10,5 \\
\hline Universidades & 11,6 & 10,4 & 24,0 & 11,3 \\
\hline Centros de Capacitação & 20,2 & 14,8 & 16,8 & 16,7 \\
\hline Instituições de Testes, Ensaios e Certificações & 10,6 & 16,7 & 23,1 & 14,9 \\
\hline Redes de Informações Informatizadas & 27,1 & 35,3 & 52,3 & 33,1 \\
\hline
\end{tabular}

Fonte: Pintec 2000

O uso desta tipologia nos dados da Pintec (tabela 6, a seguir) indica que as informações provenientes de $P \& D$ são consideradas fundamentais, principalmente pelas indústrias difusoras de progresso técnico e com capacidade competitiva ( 23,7\% atribuem importância ao setor de $\mathrm{P \& D}$ ). Já a classe de indústria com deficiências competitivas referencia menor importância a esta fonte. Como podemos observar, apenas $8,3 \%$ das indústrias pertencentes a esta classe consideram as informações de P\&D relevantes.

Quanto ao uso de fontes de informação externas, podese observar que, de modo geral, as classes de indústrias classificadas como difusoras de progresso técnico e com capacidades competitivas atribuem maior importância às informações advindas destas fontes. Como era de se esperar, nos grupos de indústrias difusoras e com capacidades competitivas, as informações provenientes de universidades e institutos de pesquisa, instituições de testes, ensaios e certificações, licenças e patentes apresentam grau de importância substancialmente maior, sugerindo maior uso de conhecimentos técnico-científico por parte destas indústrias no desenvolvimento de inovação tecnológica. Pode-se observar também que nas indústrias difusoras, a relevância das informações provindas de feiras e exposições e redes de informações informatizadas é mais expressiva, se comparada às provenientes das indústrias com capacidades competitivas. Como observado em tópicos anteriores, as informações de outras áreas internas à empresa são intensivamente utilizadas pelas empresas inovadoras, e observa-se aqui a predominância desta fonte interna nas difusoras de progresso técnico e com capacidades competitivas.

Os resultados da pesquisa sugerem, portanto, que as indústrias inovadoras brasileiras, ao realizarem maior uso de informações provenientes de fontes associadas ao mercado como fornecedores, clientes ou consumidores, estão mais propensas à promoção de inovações incrementais. Esse tipo de inovação, como ressaltado anteriormente, resulta em boa parte de melhorias sugeridas pelos usuários de produtos ou serviços ofertados pelas indústrias.

\section{CONSIDERAÇÕES FINAIS}

A partir da análise do papel da informação em ciência, tecnologia e inovação na política brasileira na década de 1990, podemos verificar a crescente preocupação e reconhecimento da importância da informação em ciência, tecnologia e informação para o desenvolvimento socioeconômico brasileiro. Como observado nesta pesquisa, o baixo nível de investimentos em CT\&I no Brasil, por parte do setor privado, desperta a premente necessidade da criação de políticas públicas e parcerias entre empresas, governo e universidades e institutos de pesquisa, como mecanismos de estímulo ao desenvolvimento da inovação tecnológica.

Quanto à percepção das indústrias com relação à importância das fontes de informação, convém destacar que a oferta de informação para a geração de inovação 
Estudo do uso de fontes de informação para inovação tecnológica na indústria brasileira

\section{TABELA 6}

Percentual de empresas industriais inovadoras que atribuíram importância alta / média às fontes internas e externas de informação, segundo a classificação dos setores adotada por Coutinho e Ferraz - Brasil,1998-2000

\begin{tabular}{|c|c|c|c|c|c|}
\hline \multirow{2}{*}{ FONTES INTERNAS E EXTERNAS } & \multicolumn{5}{|c|}{ Classes de Setores } \\
\hline & Com deficiências & Com capacidade & Difusores & Outros & Total \\
\hline Departamento de P\&D & 8,3 & 18,3 & 23,7 & 12,4 & 13,1 \\
\hline Outras Empresas do Grupo & 3,8 & 9,4 & 12,8 & 6,2 & 6,5 \\
\hline Fornecedores & 69,4 & 66,8 & 61,0 & 61,5 & 66,0 \\
\hline Clientes ou Consumidores & 55,5 & 61,9 & 71,1 & 60,0 & 59,7 \\
\hline Empresas de Consultoria & 9,6 & 10,7 & 13,3 & 10,6 & 10,5 \\
\hline Universidades e Institutos de Pesquisa & 7,5 & 14,5 & 14,6 & 14,6 & 11,3 \\
\hline Centros de Capacitação & 18,7 & 12,6 & 16,1 & 16,4 & 16,7 \\
\hline Instituições de Testes, Ensaios e Certificações & 11,1 & 19,0 & 21,7 & 15,2 & 14,9 \\
\hline Licenças e Patentes & 6,0 & 7,3 & 6,9 & 6,6 & 6,5 \\
\hline
\end{tabular}

Fonte: Pintec, 2000

por meio de fontes de informação não promove o seu uso efetivo. Nesse contexto, o cenário das indústrias brasileiras, analisadas quanto à intensidade e a diversidade do uso das fontes de informações para inovação, permitiu observar que a relevância atribuída principalmente às informações provenientes de atividades baseadas no desenvolvimento e incorporação de conhecimentos científicos reflete-se, sobretudo, no desempenho competitivo das indústrias. A informação, quando percebida e assimilada, possibilita a criação ou aperfeiçoamento de um produto e/ou processo produtivo.

É fundamental destacar que o caráter secundário da importância do uso de informações do departamento de $P \& D$ e das universidades e institutos de pesquisa, além de evidenciar a pouca preocupação com as atividades formais de pesquisa, reflete-se sobretudo em baixa participação das indústrias brasileiras na promoção de inovações revolucionárias. Estas inovações são instrumentos que, além de melhorar a dinâmica econômica, promovem a sustentabilidade para o desenvolvimento econômico.

É inquestionável a necessidade de as indústrias brasileiras conhecerem, consultarem e fundamentalmente utilizarem informações de fontes variadas para a geração de inovações tecnológicas. As dificuldades referentes ao reconhecimento da importância do uso de fontes de informação como universidades e institutos de pesquisa refletem-se claramente na débil atividade inovativa e despertam a atenção para a reflexão sobre o cenário atual das indústrias brasileiras.

\section{Artigo, recebido em 08/03/2005 e aceito para publicação em 15/08/2005.}

Agradecemos as sugestões e comentários dos parecedistas com relação à versão anterior deste trabalho. As lacunas e limitações eventualmente existentes na presente versão são da exclusiva responsabilidade dos autores. 


\section{Cibele Roberta Sugahara/Paulo de Martino Jannuzzi}

\section{REFERÊNCIAS}

ARAÚJO, V. M. R. H. de. Estudo dos canais informais de comunicação técnica: seu papel na transferência de tecnologia e na inovação tecnológica. Ciência da Informação, Brasília, v. 8, n.2, p. 79-100, 1979.

- A comunicação técnica na administração de pesquisa e desenvolvimento. In.: MARCOVITCH, J. Administração em ciência e tecnologia. São Paulo: Edgard, 1983. p. 277-296.

CONFEDERAÇÃO NACIONAL DA INDÚSTRIA (Brasil). Demanda por informação tecnológica pelo setor produtivo. Rio de Janeiro, 1996. 64 p.

COUTINHO, L.; FERRAZ, J. C. (Coord.). Estudo da competitividade da indústria brasileira. 3. ed. Campinas: Papirus, 1995. 510 p.

DAHLMAN, C. J. A economia do conhecimento: implicação para o Brasil. In: VELLOSO, J. P. dos R. O Brasil e a economia do conhecimento. Rio de Janeiro: José Olympio, 2002. p. 377-390.

FRANÇA, R. O. Patente como fonte de informação tecnológica. Perspectivas em Ciência da Informação, Belo Horizonte, v. 2, n. 2, p. 235 264, jul./dez. 1997.

FINANCIADORA DE ESTUDOS E PROJETOS (FINEP). Relatórios fundos setoriais. Disponível em: <http://www.finep.gov.br/empresa/ relatorios/fundos-setoriais/verde_amarelo.html>.

Acesso em: 28 ago. 2003.

FUNDAÇÃO DE AMPARO À PESQUISA DO ESTADO DE SÃO PAULO - FAPESP. Indicadores de ciência, tecnologia e inovação em São Paulo - 2001. São Paulo, 2002.
INSTITUTO BRASILEIRO DE GEOGRAFIA E ESTATÍSTICA (IBGE). Pesquisa industrial: inovação tecnológica 2000 (PINTEC). Rio de Janeiro, 2002. 114 p.

ORGANIZAÇÃO PARA COOPERAÇÃO E DESENVOLVIMENTO ECONÔMICO (OCDE). Medição de atividades científicas e tecnológicas: proposta de um sistema padrão para avaliação de pesquisa e desenvolvimento experimental. Brasília: CNPq, 1976.

- Medición de las actividades científicas y tecnológicas: propuesta de norma prática para encuestas de investigación y desarollo experimental. Espanha: Secretaria General del Plan Nacional de I+D, 1993.

Proposed standard practice for surveys on research and experimental development. Paris, 2002. Disponível em:

$<$ http://www.oecd.org/publication.html>.

Acesso em: 8 ago. 2003.

MARCOVITCH, J. (Coord.). Administração em ciência e tecnologia. São Paulo: Edgard Blücher, 1983. 503 p.

MUGNAINI, Rogério; JANNUZZI, Paulo de Martino; QUONIAM, Luc. Indicadores bibliométricos da produção científica brasileira: uma análise a partir da base Pascal. Ciência da Informação, Brasília, v. 33, n. 2, p. 123-131, 2004.

QUADROS, R. et al. Padrões de inovação tecnológica na indústria paulista comparação com os países industrializados. São Paulo em Perspectiva, v. 13, n. 1-2, p. 53-92, 1999.

TIDD, Joe; BESSANT, John; PAVITH, Keith. Managing innovation: integrating technological, market and organization change. England: Baffins Lane, 2001. p. 3-60. 